\title{
Research on Application System of Electronic Commerce based on Novel Mobile O2O Model
}

\author{
ShuMin Duan *, JianJun $\mathrm{Wu}$ \\ College of Tourism \\ Kaifeng University \\ Henan Kaifeng, 475000, China \\ duanshuminedu@163.com \\ * Corresponding Author
}

\begin{abstract}
O2O mode is the combination of the Internet and the opportunity to provide business information through the cable or wireless Internet. The characteristics of $\mathbf{O 2 O}$ mode is the most important promotion effect to be investigated, each transaction can be tracked. This paper firstly analyzes E-commerce platform based on O2O model. Mobile electronic commerce is a combination of the mobile communication equipment and the Internet through the smart phone and PDA. Finally, the paper presents research on application system of electronic commerce based on novel mobile $\mathrm{O2O}$ model.
\end{abstract}

Keywords- Electronic commerce; O2O model; Mobile Ecommerce; B2B; Business service platform

\section{INTRODUCTION}

The electronic commerce website will inevitably move towards the new fusion after the initial full bloom. At present, a large number of sites belong to repeat construction, the same or similar positioning, business content is similar, the result can only be the result of a small number of enterprises to win, and in a weak state of the site will eventually be eaten or closed results.

At present, the value of the industry platform for investment business, the vertical professional B2B platform will become the future of China's B2B market power, a huge development space. This platform has two characteristics: special and deep [1]. It is to concentrate all the power to create professional information platform, including the industry as a feature or a feature of international service, deep is such a platform with a unique professional nature, in the continuous exploration will generate a lot of in-depth and unique service content and profit model.

At a dizzying rate of Internet innovation, mobile Internet wave has come. $\mathrm{O} 2 \mathrm{O}$ mode has broken through the electricity supplier platform since 2013 when entered the fast lane, with the layout of $\mathrm{O} 2 \mathrm{O}$, into the community, has become a major Internet $\mathrm{Co}$ in the process of actively promoting, and community life service electricity supplier in the experience of a new attempt to integrate and develop the stage.

Compared with the traditional electronic commerce based on Internet, mobile e-commerce has the characteristics of all-weather, accuracy, security, localization, fast, convenience, recognition, stress, wide and so on. Twenty-first Century belongs to the digital era, and the development of mobile electronic commerce is to build ubiquitous and omnipotent digital ecosystem is an important part, which is conducive to create a more convenient, secure digital environment, which greatly improves productivity, improves life style and quality of life. This is not only a continuous process, but also the common progress of all walks of life, which is a combination of domestic mobile e-commerce development present situation analysis.

$\mathrm{O} 2 \mathrm{O}$ namely online to offline, refers to the wired or wireless Internet provide sales information for businesses the opportunity of the business affairs below the line and Internet combined together, the effective aggregation of groups to buy, and online pay corresponding fees, again by various forms of credentials, real-world goods or service suppliers to complete the consumer. $\mathrm{O} 2 \mathrm{O}$ mode is the most important feature is its promotion effect to be investigated; each transaction can be tracking, compared to local businesses to sell advertising, this mode of profit to much larger and is convenient for enlarging scale. The paper presents research on application system of electronic commerce based on novel mobile $\mathrm{O} 2 \mathrm{O}$ model.

\section{E-COMMERCE PLATFORM BASED ON O2O MODEL}

Community life service electricity is suppliers in the operation are mainly to make up B2C electronic business model short board: (1) credit problems, consumers buy the merchant is the most familiar of the shop. (2) Logistics and distribution problems, half an hour inside the door, without waiting for. And community life service business platform in the business model will be e-commerce operators and community property management and residential management organization form of organic combination, simple method for community residents to provide better service.

At present, the value of the industry platform for investment business, the vertical professional B2B platform will become the future of China's B2B market power, a huge development space [2]. This platform has two characteristics: special and deep. It is to concentrate all the power to create professional information platform, including the industry as a feature or a feature of international service, deep is such a platform with a unique professional nature, in the continuous exploration will generate a lot of in-depth and unique service content and profit model.

A number of third party payment companies will be so optimistic about the $\mathrm{O} 2 \mathrm{O}$ market? But it is because of the 
huge profit potential, so that entrepreneurs can be very good to achieve business value. So, in general, the $\mathrm{O} 2 \mathrm{O}$ market has what specific relative advantage? First of all, the $\mathrm{O} 2 \mathrm{O}$ model makes full use of the Internet across the region with no boundary, mass information, the advantages of massive users, while the full mining line resources, and thus promote online users and the line of goods and services transactions, buy is a typical representative of $\mathrm{O} 2 \mathrm{O}$.

In the macro level, the ultimate goal is to help enterprises establish enterprise information portal, rely on the authority of information sources and advanced intelligent agent technology, feedback timely, accurate and credible information, and ultimately achieve the smooth flow of information flow, and help enterprises to carry out scientific decision-making [3]. And in the micro level intelligent agent of the electronic commerce, the number of its users is huge but the user is not much, so it is difficult to get enough information for each user to learn, as is shown by equation (1).

$$
X(m+1)=\Phi(m) x(m, M)+\bar{w}(m)
$$

The network group purchase since entering China in 2010, there has been an explosive growth. As a manifestation of the field of electronic commerce, buying is undoubtedly the fastest growing network form of the two years. Currently, the market leader is in the independent buy site having been carried out a number of financing, and the amount is much higher than other sites, these sites are far ahead of other peers, walking in the forefront of the industry. But for other buying site, the industry reshuffle crisis has gradually approaching; many buy sites has begun to consider the transformation.

The third generation mobile communication technology (3rd-generation, 3G) is the cellular mobile communication technology which supports the high speed data transmission. $3 \mathrm{G}$ service can transmit sound and data information at the same time, the rate is generally in a few hundred Kbps or more. $3 \mathrm{G}$ is a new generation of mobile communication system, which is based on the combination of wireless communication and Internet, and there are four kinds of standards: CDMA2000, WCDMA, TD-SCDMA, WiMAX. Mobile e-commerce is still relying on the development of $3 \mathrm{G}$, and compared with $4 \mathrm{G}, 3 \mathrm{G}$ can be downloaded at the speed of $100 \mathrm{Mbps}, 2000$ times faster than dial-up, upload speed can reach $20 \mathrm{Mbps}$, and can meet the requirements of almost all users for wireless services, which will also bring many opportunities for the development of mobile e-commerce.

Currently in the electronic commerce website, $84 \%$ of online transactions do not track customers; $96 \%$ of online transactions cannot provide personalized services; $75 \%$ of online transactions can not identify repeat customers; lead to e-commerce companies cannot seize the existing customers, not to talk about the development of potential customers, the loss of this part of the important resources. With personalized customer demand increased gradually, the electronic commerce enterprise is unable to parry. When the data warehouse is enabled, the site is able to organize and store the information of customers, and when the customer visit, the data warehouse will provide the corresponding extended service to customers, so that customers can more trust the site, and thus enhance the effectiveness of the enterprise.

$$
A_{i}=\beta_{i} S+\alpha_{i}+\varepsilon_{i}, \quad i=1,2, \ldots, q
$$

$\mathrm{O} 2 \mathrm{O}$ is based on the entity store itself, the overall integration of online and offline, the core is to bring online consumers to the reality of the store, so that users' online purchase of goods and services, to the next line store to enjoy the service [4]. O2O is suitable for all businesses, and not limited to food and entertainment, such as a small number of types or special products; $\mathrm{O} 2 \mathrm{O}$ mode of community life service business platform, based on the community's quality businesses, more easily accepted by residents, eliminating the trouble of residents information search and memory. Through the establishment of a unified community life service platform in the community and it is the needs of the residents for information.

At present, the main combination of e-commerce and logistics are: customers in the online ordering, and then buyers recommend the logistics company by the buyers themselves. However, the combination of e-commerce and logistics is far more than that simple. As e-commerce is accepted by more and more consumers and become a habit, they also put forward higher requirements for logistics. The report pointed out that the next 5 years, Chinese consumers will pay more attention to the logistics service and other value-added Internet services, compared to the extent of product variety and depth of a product is slightly less.

Better community and more Wonderful Life are committed to build a community for $\mathrm{Fu}$ life in the future, into the community of users in $\mathrm{O} 2 \mathrm{O}$ mode. The market trillion level is selected based on the above analysis, the development of community business is based on trust, the localization operators operation is in line with the development of community, so the combination of the above theory puts forward in line with the actual operation of the "federal" mode, so that each community has a small and beautiful life of the community service business platform, each community is independent operation planning, community operators set up all-round, multilevel service platform, combined with a large number of community life service providers to form a new pattern of community $\mathrm{O} 2 \mathrm{O}$ business empire.

The network group purchase since entering China in 2010, there has been an explosive growth. As a manifestation of the field of electronic commerce, buy is undoubtedly the fastest growing network form of the two years. Currently, the market leader in the independent buy site has been carried out a number of financing, and the amount is much higher than other sites, these sites are far ahead of other peers, walking in the forefront of the industry. But for other buying site, the industry reshuffle crisis has gradually approaching; many buying sites has begun to consider the transformation.

Near field communication is a kind of standard communication technology, which can simplify the transaction and reduce the exchange of digital content. When a user with a near field communication device is close to the target object, the service is accessed, and the content is interactive, the establishment is connected, the payment is made, or the ticket is shown, etc. Major players 
in the mobile e-commerce, including Google, Visa and a number of leading wireless operators have invested heavily in this technology [5].

$$
\operatorname{pr}\left\{m_{i}(k+1) \mid m_{j}(k), Z(k)\right\}=\mu_{j \mid i}(k)
$$

In the boom of e-commerce booming, the industry chain has actually emerged, namely, the same is the future development of logistics supply chain. At present, the main combination of e-commerce and logistics are: customers in the online ordering, and then buyers recommend the logistics company by the buyers themselves. However, the combination of e-commerce and logistics is far more than that simple. As e-commerce is accepted by more and more consumers and become a habit, they also put forward higher requirements for logistics. The report pointed out that the next 5 years, Chinese consumers will pay more attention to the logistics service and other value-added Internet services, comparing to the extent of product variety and depth of a product is slightly less.

Intelligent agents can also be used to screen the micro level of the users' buying habits with other consumers to buy a tendency to recommend, this technology in the electronic commerce website has been mostly achieved, and technology has been relatively mature. Such as the domestic online bookstore use the membership management, the user first login and purchase activities, will be with the user interest related books in the next list, for users to buy, so that users can save time in search of interest, but also to get the users' preference to help companies for personalized advertising and product promotion.

\section{NOVEL APPLICATION SYSTEM OF MOBILE ELECTRONIC COMMERCE}

IPv6 is the next generation of internet protocol, it is proposed because with the rapid development of the Internet, IPv4 defined finite space is about to be exhausted, resulting in the expansion of the address space. Because of its 128 bit address length, it is almost not limited to provide address. This is a wireless communication and video recognition (RFID) technology to bring unlimited space for development, especially for the number of ground mobile terminals, to allocate a permanent global Ip address for each device, so it can solve the problem of mobile communication between the network and all kinds of access technology in the world.

ShopLocket is a dedicated business service platform for innovative hardware [6]. It wants to collect the latest and the most popular hardware products, to help hardware entrepreneurs docking those who seek the most cool products angel users, so that those who have already raised the site to raise funds, but also not mature enough to be able to visit the traditional electricity supplier website such as Amazon Hard Suits Inc, continue to have a platform, you can increase the exposure and acceptance. ShopLocket includes several modules. For example, its Store page, is a business website, entrepreneurs can sell a series of products on the ShopLocket, as is shown by equation (4).

$e_{1} \operatorname{S.T.} \operatorname{Max}\left(R\left(W_{j}^{\sigma}, F_{e}\right), j=1,2, \cdots, M\right)$
A series of mechanized equipment is to reduce the line of goods handling and personnel walking. Storage: after the acceptance of the device with a wireless device scanning, the system will automatically carry out a series of operations, automatic allocation to the appropriate place. Library: the system automatically completed the wave of arrangement, intelligent positioning, task allocation, a key to receive, the staff will be able to operate in the smart device until the picking, and inventory packaging, etc.. Library: such as warehouse inventory system automatic operation corresponding to the position of the corresponding goods missing, make from secondary replenishment to replenishment a replenishment action.

For these $\mathrm{O} 2 \mathrm{O}$ sites, it is now a new era of network, the answer is quicker way to get the answer, and for the time money view of the enterprise, the network cable way is more sought after. About the sale of products, businesses can expand the business through the cover line down. Network consumers are usually seen in front of $1 / 3$ things, like the sea, like the tip of the iceberg, which is a corner, but the real support is under the water, which is the real strength, there is no support below, there is no, so the electricity suppliers are the following $2 / 3$ 's real power.

E - Commerce is not only the establishment of a website, the promotion of enterprise products and image, is not a simple online shopping [7]. The real electronic commerce should be on the Internet as the core of information technology for business activities and resources processing to put it bluntly, it is the flow of information, management of value-added application. Business China in the development of each column helps companies to establish information sharing between customers and suppliers, high-speed mobile commerce and traditional operation mode change the traditional business model in the non time constraints of virtual business network transactions, as is shown in Equation (5), where 90 years of this century, has achieved remarkable results in the foreign trade sector EDL system, business information systems and manufacturing MRP system.

$$
G(x, y, \sigma)=\left(2 \pi \sigma^{2}\right)^{-\frac{1}{2}} \exp \left(-\frac{x^{2}+y^{2}}{2 \sigma^{2}}\right)
$$

The basic function of the electronic commerce intelligent recommendation system, the function of the client is to register: the main way to obtain the user information of the functional website. Successively determining user access, access to user information set, complete control of the management of the site, classification browse: according to product specifications and types classified directory, through the collection and display of massive information to ensure the information space, comprehensive and stable. It has become a measure of the size of the enterprise web site can be evaluation index.

The entire process customer can be accomplished through the remote monitoring, a lot of saving resources and cost [8]. Cargo operations require special skills of the staff, such as goods out of storage, video data acquisition and transmission, the use of equipment and storage, data collation and digital statistics. Warehouse Hardware: The international standard warehouse and it is the air 
circulation, humidity, temperature in the library according to the product category different, and it is special goods need to do clean management.

\section{APPLICATION SYSTEM OF ELECTRONIC COMMERCE BASED ON NOVEL MOBILE O2O MODEL}

As a community $\mathrm{O} 2 \mathrm{O}$ business service platform, there are hundreds of practice base; training base for more than a thousand square, rarer is also has a well-known university academic research support, community $\mathrm{O} 2 \mathrm{O}$ training school and Research Institute. Not only in a large number of practical cases to sum up experience, from the personality to find can common support, and it gets the guidance of advanced theory.

With the increasingly fierce competition in ecommerce, the role of business intelligence in e-commerce operations will gradually become important; this point from foreign mature e-commerce sites can be seen [9]. In foreign countries, the general e-commerce enterprises will have a special person responsible for data analysis and other business intelligence, such as business intelligence, as a strategic investment. From the current China's ecommerce industry, the real concern about data analysis and business intelligence is not much, but the lack of capital investment is the main reason for the enterprise. But the importance of data for e-commerce enterprises is self-evident, e-commerce oriented business intelligence management system is based on the combination of intelligent management system and online decision support system, the integration of intelligent, integrated, coordinated, networking and online decision support to the traditional business computer management system, so that it can adapt to the modern business development trend, to provide better management environment and decision support.

China's mobile communication business is developing rapidly, whether it is the communication equipment, infrastructure or the user scale to maintain a relatively fast pace of development [10]. With the development of mobile communication services, the business value of mobile Internet is gradually becoming more and more popular, thanks to the popularity of smart terminals and mobile network environment, the use of services from instant messaging, mobile reading and other relatively simple applications, expand to mobile office, electronic commerce, etc., as is shown by equation (6).

$$
\begin{aligned}
\bar{R}(m) & :=\operatorname{diag}\{\bar{R}(m, 1), \bar{R}(m, 2), \cdots, \bar{R}(m, M)\} \\
& :=\operatorname{diag}\{R((m-1) M+1), R((m-1) M+2), \cdots, R(m M)\}
\end{aligned}
$$

E-commerce as a new major application area of Internet is developing at a difficult to measure, affecting and changing every aspect of social economic life. Government, enterprises and individuals should learn from different aspects of e-commerce technology, in order to adapt to the information society. The purpose of this book is to introduce the application of electronic commerce and the related technology. The whole book is divided into ten chapters, which introduces the concept, development history and its impact on social economy, e-commerce function and its classification, electronic commerce, electronic commerce, security and control method, electronic commerce online payment tools, electronic commerce, online banking, online banking, online advertising, e-commerce development process, and finally, the prospects and Countermeasures of e-commerce in the world and our country.

$\mathrm{O} 2 \mathrm{O}$ model can be directly used in the business of marketing results and tracking assessment, to avoid the traditional marketing model of the promotion effect is not predictable, $\mathrm{O} 2 \mathrm{O}$ will online orders and line consumption, all of the consumer behavior can be accurate statistics, and thus attract more businesses to provide consumers with more quality products and services.

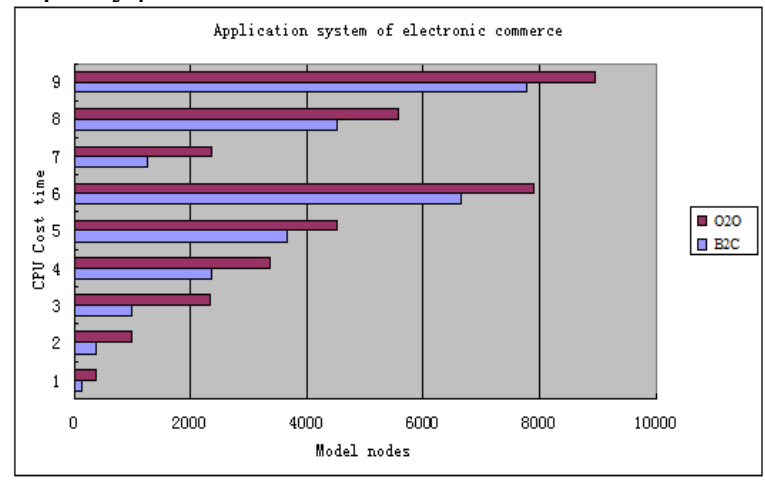

Figure 1. Research on application system of electronic commerce based on novel mobile $\mathrm{O} 2 \mathrm{O}$ model.

Mobile e-commerce payment system is still not perfect for mobile e-commerce payment system has always been the most concern is the most concern of a problem, which is directly related to the direction of gold. Electronic payment ring once appeared, it is likely to result in property two empty. Current mobile e-commerce major payment methods are deducted from the bill, the third party payment platform and the opening of the exclusive account of three ways. However, the payment of mobile electronic commerce in China mainly uses the second way, namely, the use of similar payment of treasure, money paid through such third party platform in a number of security vulnerabilities, can not give people a sense of trust.

China has formed the world's largest mobile phone users, SMS service in China to open a huge market, and successfully combined with the Internet, creating a unique Chinese e-commerce model. With the rapid development of the China Mobile communication network construction, the various types of business services provided by wireless and mobile will continue to emerge. There is reason to expect that the Chinese users' acceptance of mobile commerce and demand will be higher than other countries and regions.

\section{SUMMARY}

As China's first community $\mathrm{O} 2 \mathrm{O}$ business service platform, in the last mile of the Internet of things, half an hour life circle quality home products and services are provided, determiningto become the industry standard $\mathrm{O} 2 \mathrm{O}$. With the gradual upgrading of mobile devices and wireless communication technology in China, more and more people began to use mobile phones, tablet computers and other mobile devices for online shopping activities; mobile e-commerce ushered in unprecedented development opportunities meet a new challenge in the field. The paper presents research on application system of 
electronic commerce based on novel mobile $\mathrm{O} 2 \mathrm{O}$ model. In $\mathrm{B} 2 \mathrm{C}$ e-commerce, online suppliers and product volume growth will soon make customers difficult to choose, at this time they will need to have a smart product comparison and inquiry, the ability to provide assistance to help.

\section{REFERENCES}

[1] Mehrbakhsh Nilashi, Mohammad Fathian, Mohammad Reza Gholamian, Othman bin Ibrahim, Amir Talebi , Norafida Ithnin, "A Comparative Study of Adaptive Neuro Fuzzy Inferences System (ANFIS) and Fuzzy Inference System (FIS) Approach for Trust in B2C Electronic Commerce Websites", JCIT, Vol. 6, No. 9 , pp. $25 \sim 43,2011$

[2] Haidong ZHONG, Shaozhong ZHONG, Xiaojun ZHONG, Xiaohong HE, Jie YIN, "Study on LBS Driven Mobile Ecommerce: Key Issues and Technological Architecture", JDCTA, Vol. 6, No. 13, pp. $460 \sim 469,2012$.

[3] Lijun Bu, "On Economic Efficiency Framework of E-Commerce Based on B2B Mode", AISS, Vol. 5, No. 4, pp. $457 \sim$ 463, 2013.
[4] Liao Fang-nan, "The Study on Management Accounting in Electronic Commerce based on Markov Process", JDCTA, Vol. 6 , No. 2, pp. $241 \sim 247,2012$.

[5] Feng TIAN, Jinpei YAN, "Study of Mobile E-Commerce Safety System Model Based on Petri Net", JCIT, Vol. 8, No. 10, pp. 33 41, 2013

[6] Han-Chen Huang, Guan-Ya Shen, "Applying the Fuzzy Analytic Hierarchy Process to the Analysis of Leisure Business Service Failure Weights", IJACT_CST, Vol. 4, No. 22, pp. $813 \sim 822$ 2012.

[7] Yonglark Sohn, Sangwon Lee, Namgyu Kim, "Design of Lifelog Safety Management for Electronic Commerce", IJACT, Vol. 5, No. 12, pp. $130 \sim 137,2013$

[8] Sahar Sohrabi, Bahman Nikkhahan, "Comparison between Cooperative and Non-cooperative Game in Seller Side B2B Electronic Market", IJIPM, Vol. 2, No. 2, pp. 40 47, 2011.

[9] Kun Fan, Jing Wu, Xinyu Ma, Weijia You, "Influencing Factors Analysis of Forest Farmers' Adoption of Forestry Electronic Commerce", JCIT, Vol. 8, No. 3, pp. $350 \sim 357,2013$

[10] Xiaoyi Deng, "An Enhanced Artificial Bee Colony Approach for Customer Segmentation in Mobile E-commerce Environment", IJACT, Vol. 5, No. 1, pp. $139 \sim 148,2013$ 